\title{
Moment Capacity of Reinforced Concrete Beam Including Uncertainties
}

\author{
Divya Kolasani ${ }^{1}$, A. Venkat Reddy ${ }^{2}$ \\ ${ }^{1}$ CVR College of Engineering, Department of Civil Engineering, Hyderabad, INDIA \\ Email: divyakolasani@gmail.com \\ ${ }^{2}$ CVR College of Engineering, Department of Civil Engineering, Hyderabad, INDIA \\ Email: venkat.reddy@cvr.ac.in
}

\begin{abstract}
The purpose of this paper is to evaluate the reliability of reinforced concrete beam designed under the provisions of IS: 456- 2000 including the numerous sources of uncertainties in the load and resistance-related parameters, which are usually not included in the theoretical method of calculating the Ultimate Moment Capacity of a reinforced beam. Based upon the statistical results, the possible random variables are obtained from large experimental data. In this attempt, the probability of failure of a reinforced concrete beam is obtained by calculating Ultimate Moment Resisting Capacity. These random variable distribution curves, incorporating various uncertainties are included, excluding the partial safety factors, using a high level computing language i.e., MATLAB is used for our work.
\end{abstract}

Keywords: Reliability, Ultimate moment carrying capacity, Reinforced Concrete Beam, Partial Safety Factors.

\section{INTRODUCTION}

In this theoretical method of calculating the ultimate moment carrying capacity of a reinforced concrete (RC) beam, we include partial safety factors for materials and neglect the various uncertainties included during the construction like variation in material properties, geometric dimensions and other load and resistance parameters which are random in nature.

Various studies have been conducted globally in order to obtain the probabilistic approach of variations in the design parameters. Based upon the large experimental data available the nature, distribution of random variables is attained. Using these possible random variables, a large mathematical and experimental data is generated using the various simulation techniques available and the reliability of a given structure is calculated for an array of inputs given.

\section{Research Methodology}

Ultimate Moment of Resistance (Mur) of an RC beam without considering the partial safety factor:

The code has adopted the usage of partial safety factors as given below:

$$
\mathrm{R}_{\mathrm{d}} \geq \mathrm{S}_{\mathrm{d}}
$$

$R_{d}$ is the design resistance is computed using reduced material strengths, involving two separate partial safety factors $\gamma_{c}$ (for concrete) and $\gamma_{s}$ (for steel). $S_{d}$ is the design load effect computed for enhanced loads involving separate partial safety factors. It may be noted that the partial safety factors of materials $\left(\mathrm{\gamma}_{\mathrm{c}}, \mathrm{\gamma}_{\mathrm{s}}\right)$ are greater than unity and are the dividing factors while the multiplication factor $\phi$ is less than unity leading to overestimation of loads and underestimation of material strength resulting in improved safety. But in this case the partial safety factors are not taken into consideration. The nominal strength of concrete $0.67 \mathrm{fck}$ and nominal yield strength of steel (fy) on the side of resistance and nominal load effects are taken as such providing nominal results.

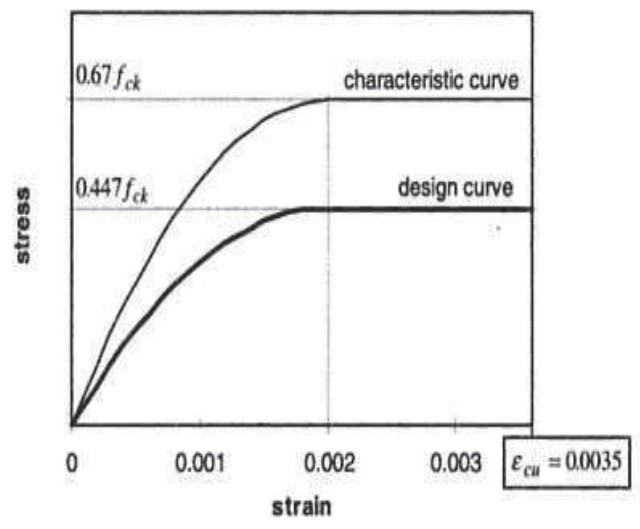

Figure: 1 Characteristic and design stress- strain curves of concrete

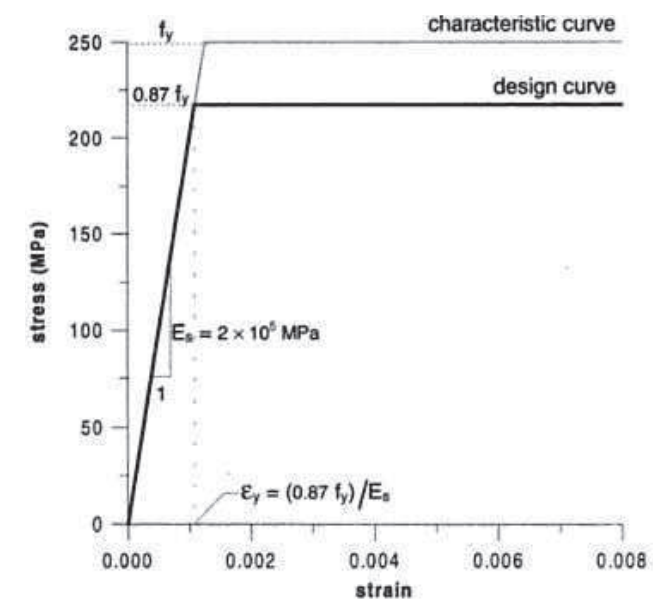

Figure: 2 Characteristic and design stress- strain curves for Fe 250 grade cold worked steel. 


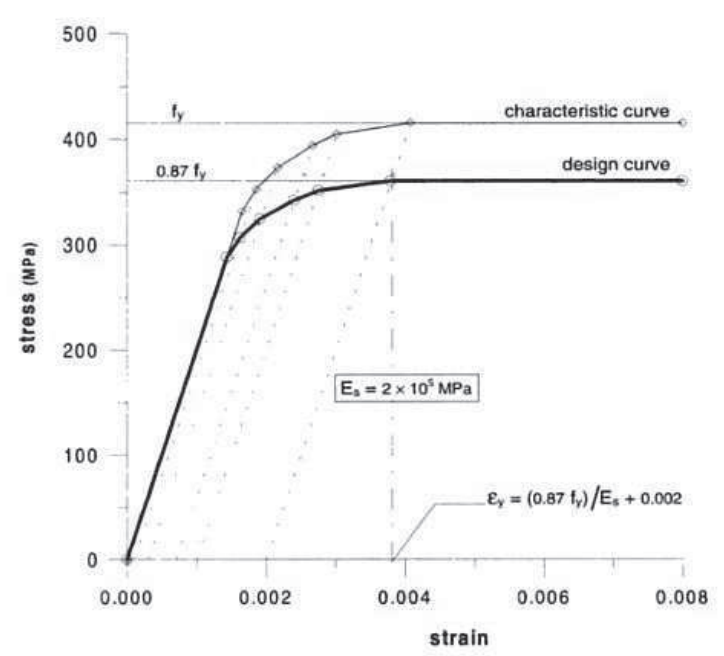

Figure: 3 Characteristic and design stress- strain curves for Fe 415 grade cold worked steel.

The characteristic curve is taken into consideration

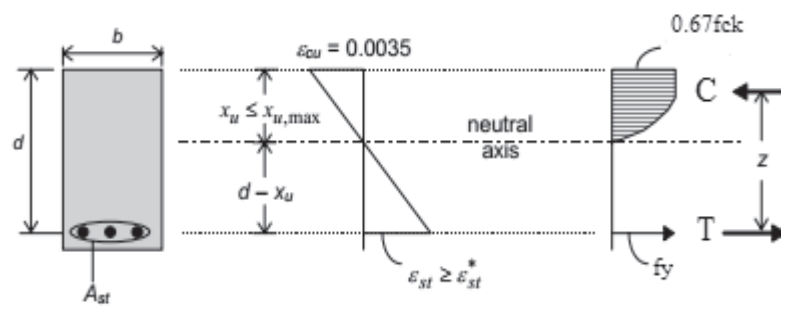

(a) beam section

(b) strains

(c) stresses

\begin{tabular}{|c|c|c|c|}
\hline Steel Grade & Fe 250 & Fe 415 & Fe 500 \\
\hline $\mathrm{X}_{\mathrm{u}, \max } / \mathrm{d}$ & 0.518 & 0.462 & 0.4375 \\
\hline
\end{tabular}

rather than the usual design curve, for computing the ultimate moment of resistance of a beam.

\section{A) Analysis of Singly Reinforced Rectangular Sections}

Analysis of a given reinforced concrete section at ultimate limit state of flexure implies the determination of the ultimate moment of resistance $\mathbf{M}_{\mathbf{u r}}$ of the section, which is given by the couple resulting from flexural stresses:

Figure: 4 Behaviour of singly reinforced rectangular section in flexure

$$
\mathrm{M}_{\mathrm{ur}}=\mathrm{C} \cdot \mathrm{Z}=\mathrm{T} \cdot \mathrm{Z}
$$

$\mathrm{Z}=$ Lever arm distance

$$
T=f_{s t} \cdot A_{s t}
$$

$f_{s t}=f_{y}$, for $X_{u} \leq X_{u, \max }$ and the line of action of $T$ corresponds to the level of the centroid of the tension steel.
In order to compute the magnitude of the resultant compressive forces, the concrete stress block in compression must be analysed such that nominal strength of concrete $0.67 \mathrm{fck}$ is taken into calculations rather than design strength of concrete $0.447 \mathrm{fck}$. Therefore the resulting compressive force for a given beam with width 'b', effective depth ' $\mathrm{d}$ ' and neutral axis at a depth of $\mathrm{X}_{\mathrm{u}}$ from the topmost compression fibre is given as:

$$
\mathrm{C}=0.542 \text {.fck.b.Xu }
$$

The line of action of ' $\mathrm{C}$ ' is the centroid of the stress block located at a distance $\mathrm{X}$ ' from the extreme fibre of concrete experiencing the maximum compressive strain.

$$
X^{\prime}=0.416 X_{u}
$$

(a) Depth of Neutral Axis:

The depth of neutral axis is such that where $\mathrm{C}=\mathrm{T}$, satisfying the equilibrium of forces.

When $X_{u} \leq X_{u, \max }, f_{s t}=f_{y}$,

$$
X_{u}=\frac{f_{s t} * A_{s t}}{0.542 * f_{c k} * b}
$$

When $\mathrm{X}_{\mathrm{u}}>\mathrm{X}_{\mathrm{u}, \max }, \boldsymbol{\Xi}_{\boldsymbol{s t}}<\mathbf{\Xi} \mathbf{w}_{\text {st, }}$, implies that steel may not yield at the ultimate limit state in flexure. Therefore $f_{s t}$ $<\mathrm{f}_{\mathrm{y}}$, the true location of neutral axis is obtained by trial and error method, also called as strain compatibility method,

\section{(b) Ultimate Moment of Resistance Without Considering Partial Safety Factors}

The lever arm for a singly reinforced rectangular section is given by:

$$
\begin{gathered}
\mathrm{Z}=\mathrm{d}-0.416 \mathrm{X}_{\mathrm{u}} \\
\mathrm{M}_{\mathrm{ur}}=0.542 . \mathrm{f}_{\mathrm{ck}} * \mathrm{~b} * \mathrm{X}_{\mathrm{u}} *\left(\mathrm{~d}-0.416 \mathrm{X}_{\mathrm{u}}\right)
\end{gathered}
$$

$\mathrm{M}_{\mathrm{ur}}=\mathrm{f}_{\mathrm{st}} \cdot \mathrm{A}_{\mathrm{st}}\left(\mathrm{d}-0.416 \mathrm{X}_{\mathrm{u}}\right)$

\section{(c) Limiting Depth of Neutral Axis}

Table 1. Limiting depth of neutral axis without considering partial safety factors

(d) Percentage of steel

Percentage of tension steel is given by:

$$
P_{t}=\frac{A_{g t} * 1000}{b * d}=\frac{0.542 f_{g k} * X=100}{f_{y} * d}
$$

When $\mathrm{X}_{\mathrm{u}}=\mathrm{X}_{\mathrm{u}, \max }$

$\mathrm{P}_{\mathrm{t}, \mathrm{lim}}=\frac{0.542 \mathrm{f}_{\mathrm{ck}} * \mathrm{X}_{\mathrm{u}_{\mathrm{z}} \max } * 100}{\mathrm{f}_{\mathrm{y}} * \mathrm{~d}}$

B) Analysis of Doubly Reinforced Rectangular Sections 
In a doubly reinforced section the condition of force equilibrium applied is:

$$
\mathrm{C}_{\mathrm{c}}+\mathrm{C}_{\mathrm{s}}=\mathrm{T}
$$

Where:

$\mathrm{C}_{\mathrm{c}}=0.542 * \mathrm{f}_{\mathrm{ck}} * \mathrm{~b} * \mathrm{X}_{\mathrm{u}}$ (Resultant compressive force in concrete)

$$
\mathrm{C}_{\mathrm{s}}=\left(\mathrm{f}_{\mathrm{sc}}-0.67 \mathrm{f}_{\mathrm{ck}}\right) \cdot \mathrm{A}_{\mathrm{sc}}
$$

$\mathbf{T}=$ Resultant tension force in steel $=\mathrm{f}_{\mathrm{st}} \cdot \mathrm{A}_{\mathrm{st}}$

(a) Depth of neutral axis

Case (i) $P t>P c$

Considering the force equilibrium condition and without considering partial safety factors the neutral axis depth for a doubly reinforced beam in which percentage tension steel $(\mathrm{Pt})$ is greater than the percentage compression steel $(\mathrm{Pc})$ can be calculated as that of a singly reinforced beam. Assuming both the tension and compression steel yielded and hence fst $=$ fy $=$ fsc, the neutral axis depth is given by

$X_{\mathrm{u}}=\frac{f_{\mathrm{gt}} A_{\mathrm{gt}}-\left(f_{\mathrm{gs}}-0.67 f_{\mathrm{sk}}\right) A_{\mathrm{gc}}}{0.542 . f_{\mathrm{ck}} \cdot \mathrm{b}}$

The conditions are applicable as discussed earlier in singly reinforced beam for $\& \mathrm{f}_{\mathrm{sc}}$, when necessary strain compatibility method is to be employed.

Case (ii) $P t<P c$

When percentage of tension steel is much less than percentage of compression steel leading to an over compression reinforced beam section, the tension resistance of the beam becomes very less. When the $\mathrm{P}_{c}$ is much greater than $\mathrm{P}_{\mathrm{t}}$, there exists a tendency of the neutral axis depth to move much closer towards the compression steel and at times causes the reversal of stresses in the compression steel.

Hence, the above furnished formula for calculating the $\mathrm{X}_{\mathrm{u}}$ cannot be used directly. Hence trial and error approach for finding the depth of neutral axis can be applied. For a given beam the force equilibrium conditioned is verified by taking a continuous series of values for $\mathrm{X}_{\mathrm{u}}$ with any required increment starting from zero. Corresponding strains and stresses are calculated and the value of $\mathrm{X}_{\mathrm{u}}$, where the condition of force equilibrium is satisfied is taken as the true location of neutral axis depth. This method is very flexible and is applicable for any type of beam given but when done manually, it is very tedious.

\section{(B) Ultimate Moment of Resistance Without Considering} Partial Safety Factors

The moments of $\mathrm{C}_{\mathrm{c}}$ and $\mathrm{C}_{\mathrm{s}}$ about the centroid of tension steel give the ultimate moment of resistance:

$M_{u r}=0.542 . f_{c k} \cdot b \cdot X_{u}\left(d-0.416 X_{u}\right)+\left(f_{s c}-0.67 f_{c k}\right) A_{s c}$ (d-d')
Where: d'= Distance between the centroid of the compression steel and the extreme fibre in the concrete.

$\mathbf{f}_{\mathrm{sc}}=$ Stress in the compression steel

Other parameters remain the same as discussed earlier.

\section{EXPERIMENTAL Procedure}

Algorithm for finding the Ultimate Moment of Resistance of RC beams without considering partial safety factors:

The furnished algorithm given below is applicable for both singly reinforced and doubly reinforced beam (including case (i) \& case (ii)). Based on this algorithm, a MATLAB code is generated to find the ultimate moment of resistance of any beam for any percentage of tension and compression steel provided, without considering the factor of safety of materials.

In the following algorithm, the true neutral axis depth is obtained by trial and error approach by equating the force equilibrium condition for values from 0.001 to 1 for the ratio of neutral axis to effective depth of beam and the program terminates when the condition is satisfied. Then the ultimate moment of resistance is calculated corresponding to the true neutral axis depth.

1) Given beam of width (b), effective depth (d), distance between the centroid of compression steel and the topmost compression fibre $\left(d^{\prime}\right)$, percentage of tension steel $\left(\mathrm{P}_{t}\right)$, percentage of compression steel $\left(\mathrm{P}_{\mathrm{c}}\right)$, grade of steel $\left(\mathrm{f}_{\mathrm{y}}\right)$ and grade of concrete $\left(\mathrm{f}_{\mathrm{ck}}\right)$

2) For $X_{u} / d$ value starting from 0.001 to 1 , strains in tension and compression steel are calculated using respective formulae.

3) Using the strain values obtained the stresses in the tension and compression steel are calculated from the respective nominal stress strain curve of the steel (as per grade of steel provided). For Fe 415 \& Fe 500, co-ordinate points for nominal stress and their respective strains in the parabolic path of nominal stress-strain curve, as shown in the figure 5 , are given below in table 2 .

4) Assuming the parabolic path to be continuous fragmented straight line, stress values are calculated using piece-wise linear interpolation. The stress points in the curve chosen are given, along with their respective proof strain values, in table 2

TABLE 2

SALIENT Points On The STResS-STRain CURVE For COLD-Worked STEEL

\begin{tabular}{|l|l|l|l|l|l|l|}
\hline $\begin{array}{l}\text { Nominal } \\
\text { stress }\end{array}$ & $0.8 f_{y}$ & $0.85 f_{y}$ & $0.9 f_{y}$ & $0.95 f_{y}$ & $0.975 f_{y}$ & $f_{y}$ \\
\hline $\begin{array}{l}\text { Proof } \\
\text { strain }\end{array}$ & 0 & 0.0001 & 0.0003 & 0.0007 & 0.001 & 0.002 \\
\hline
\end{tabular}




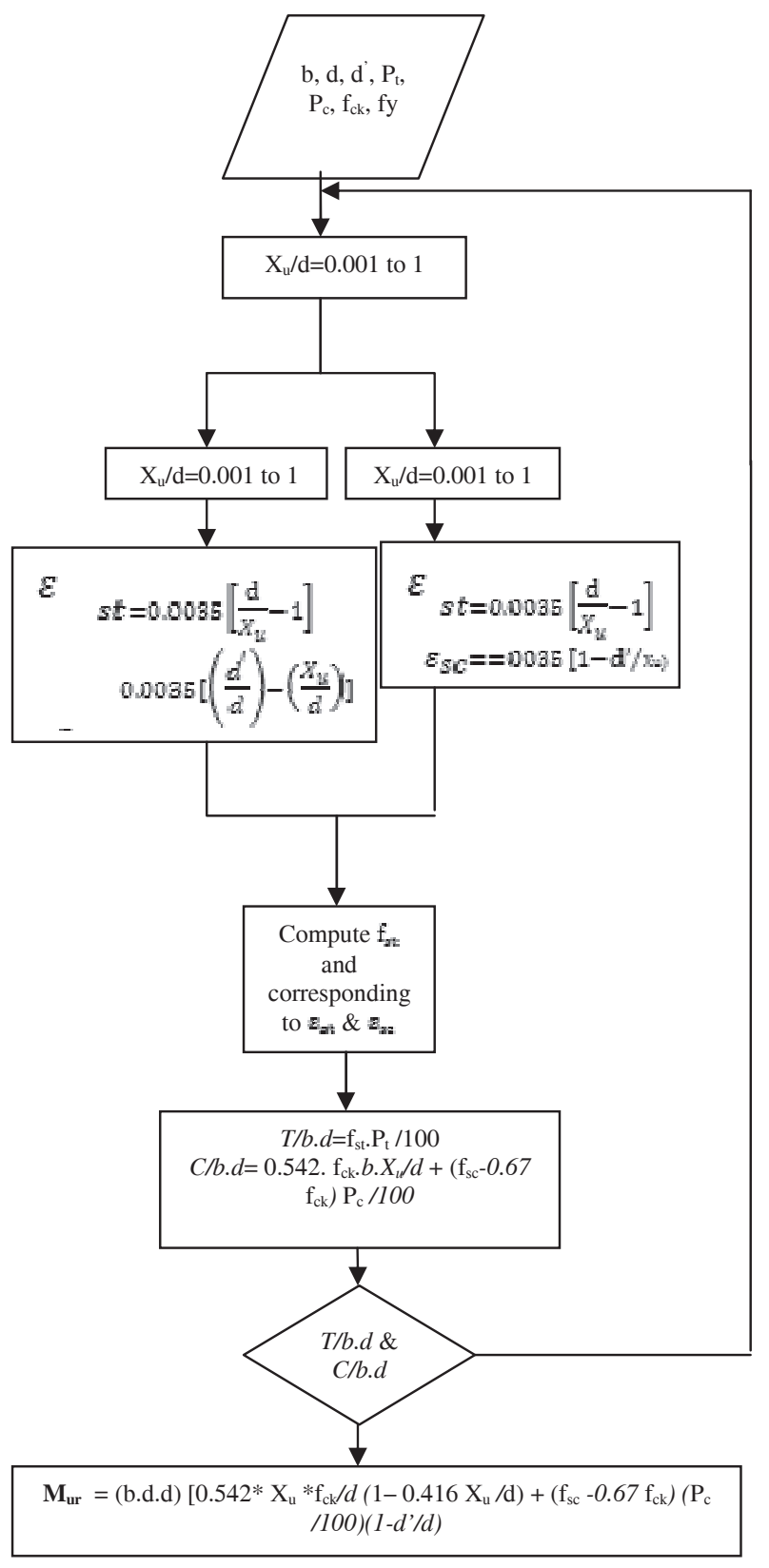

Figure 5 Algorithm for calculating the moment carrying capacity of a Reinforced Concrete beam.
TABLE 3

Characteristic StRess-Strain VAlues

\begin{tabular}{|c|l|l|l|}
\hline \multicolumn{2}{|c|}{ Fe 415 } & \multicolumn{2}{c|}{ Fe 500 } \\
\hline Stress & \multicolumn{1}{|c|}{ Strain } & \multicolumn{1}{|c|}{ Stress } & \multicolumn{1}{c|}{ Strain } \\
\hline 0.00166 & 332.005 & 0.002 & 399.97 \\
\hline 0.00186 & 352.705 & 0.002225 & 425.385 \\
\hline 0.002167 & 373.52 & 0.00255 & 449.995 \\
\hline 0.00267 & 394.22 & 0.003075 & 474.95 \\
\hline 0.00302 & 404.57 & 0.0034375 & 487.485 \\
\hline 0.004075 & 415.036 & 0.0045 & 500.02 \\
\hline
\end{tabular}

5) The tension and compression forces for the corresponding stresses are calculated and force equilibrium condition is checked. If not satisfied, iterations continue for the next value for $\mathrm{X}_{\mathrm{u}} / \mathrm{d}$. If force equilibrium is satisfied, then calculate the ultimate moment of resistance of the beam using the formula for $\mathrm{M}_{\mathrm{ur}}$ aforementioned.

Note: While considering the ratio of neutral axis to the effective depth of the beam, one must be very cautious about the strain compatibility equation for computing the strains in compression steel. The reason is that there will be a change in similar triangles and accordingly their formulae for calculating the strains.

(i) When $X_{u} / d$ lies between 0.001 and 0.1 (neutral axis is considered to be above compression steel), then the compression steel will be in tension. Hence, as per similar triangles, the formula for finding the strain in compression steel is obtained as given below:

$$
\varepsilon_{\mathrm{gC}}=\frac{0.0035\left[\left(\frac{\mathrm{d}^{\prime}}{\mathrm{d}}\right)-\left(\frac{\mathrm{X}_{\mathrm{u}}}{\mathrm{d}}\right)\right]}{\mathrm{X}_{\mathrm{u}} / \mathrm{d}}
$$

(ii) When $\mathrm{X}_{\mathrm{u}} / \mathrm{d}$ is greater than 0.1(i.e., neutral axis is below the compression steel), then the compression steel will always be in compression and applying the strain compatibility (similar triangles), the formula for finding strain in compression steel is

$$
\mathrm{E}_{s c=0.0035\left[1-\mathrm{d} / \mathrm{X}_{\mathrm{u}}\right]}
$$

Using the above algorithm, a MATLAB code is generated to calculate the ultimate moment of resistance without considering the partial safety factors for materials for any beam, given all its input. The generated code is provided in the appendix for further review.

\section{A) Uncertainties in Construction}

In analysis and design calculations, the major variables subjected to high degree of uncertainty considered in our study are: 
1. Loads

2. Material Properties

3. Dimensions

There are many other unforeseen variable factors which affects the strength and serviceability of structures which we have not taken into account in our investigation. For practical and quantitative representation of reliability, statistical and probabilistic analysis is quite rational. Recent attempts include the application of fuzzy logics also.

\section{B) Deterministic and Probabilistic Approaches}

In the presence of uncertainty, it is not simple to satisfy the basic design requirements. The design depends upon the following two parameters:

1. Load on the structure ' $S$ ' (lifetime maximum)

2. Ultimate resistance ' $R$ ' (capacity of structure)

Both $\mathrm{S} \& \mathrm{R}$ are expressed in terms of stress resultant such as bending moment at critical section, and are treated as statistically independent random variables; their randomness is characterized by their means $\left(\boldsymbol{\mu}_{\boldsymbol{S}}, \boldsymbol{\mu}_{\boldsymbol{R}}\right)$, standard deviations $\left(\boldsymbol{\sigma}_{\boldsymbol{F}}, \boldsymbol{\sigma}_{\boldsymbol{R}}\right)$ and corresponding probability density functions.

If $\mathbf{S}<\mathbf{R}$, the structure is expected to be safe, and if $\mathbf{S}>\mathbf{R}$, the structure is expected to fail. The probability of failure can be calculated as follows:

$\mathbf{P}_{\mathrm{f}}=$ Probability $[\{\mathrm{R}<\mathrm{S}\} \cap\{0<\mathrm{S}<\infty\}]$

Reliability Analysis:

A rational and quantitative solution to the problem of 'adequate safety' can be obtained by quantifying the acceptable risk in terms of target probability of failure or target reliability.

Reliability is expressed as the complement of the probability of failure, i.e.

Reliability $=\left(\mathbf{1}-\mathbf{P}_{\mathrm{f}}\right)$

Evaluating the probability of failure $\left(\mathbf{P}_{\mathbf{f}}\right)$ (or the reliability) underlying a given structure is termed as reliability analysis, whereas designing a structure to meet the target reliability is termed as reliability design.

Reliability analysis of moment capacity of RC beam:

Theoretically we do not consider the deviation of $\mathbf{M}_{\mathbf{u r}}$ of a given RC beam, but practical cases include many uncertainties. Thus ultimate moment of resistance for the beam can never be a fixed (calculated) value. The possible cases of uncertainties which have been taken into consideration are:

1.) Dimensions of beam $(b, d)$

2.) Grade of concrete $\left(f_{c k}\right)$

3.) Grade of steel $\left(f_{y}\right)$

4.) Percentage of tension steel provided $\left(\mathrm{P}_{t}\right)$

5.) Percentage of compression steel provided $\left(\mathrm{P}_{\mathrm{c}}\right)$

6.) Load acting on the beam (Q)

All these factors vary accordingly from their nominal values over a range of deviation, and their respective type of probability distribution patterns. As per results of statistical analysis of variation of these parameters, mean, coefficient of variation (C.O.V) and probability distributions are obtained by various established studies and a series of random variables can be generated which represent the most probable values of these parameters with in which they lie. Table 4 gives the results of statistical analysis of variation of parameters taken into consideration for the generation of random variables.

TABLE 4

RESULTS OF STATISTICAL ANALYSIS TAKEN INTO CONSIDERATION

\begin{tabular}{|l|c|c|c|}
\hline \multicolumn{1}{|c|}{ Variable } & Mean & C.O.V & $\begin{array}{l}\text { Probability } \\
\text { distribution }\end{array}$ \\
\hline $\begin{array}{l}\text { Compressive } \\
\text { strength of } \\
\text { concrete (Nominal } \\
\text { mix- M20) }\end{array}$ & 19.54 & 0.21 & Normal \\
\hline $\begin{array}{l}\text { Yield Strength of } \\
\text { steel }\end{array}$ & $\begin{array}{l}\text { Fe } 250-320 \\
\text { Fe } 415-469\end{array}$ & 0.1 & Normal \\
\hline Dead load (D) & 1.05D & 0.1 & Normal \\
\hline $\begin{array}{l}\text { Flexural } \\
\text { reinforcement }\end{array}$ & $\begin{array}{c}\text { Mean of } \\
\text { requided/ }\end{array}$ & 0.04 & Lognormal \\
\hline
\end{tabular}

TABLE 5

RESUlTS OF STATISTICAL ANALYSIS OF VARIATION IN DIMENSIONS

\begin{tabular}{|c|c|c|c|}
\hline Beam & $\begin{array}{c}\text { Mean } \\
\text { Deviation }\end{array}$ & $\begin{array}{c}\text { Standard } \\
\text { Deviation }\end{array}$ & Size range $(\mathrm{mm})$ \\
\hline Breadth & +10.29 & 9.47 & $200-350$ \\
\hline Effective depth & +6.25 & 3.79 & $250-370$ \\
\hline Overall depth & +14.37 & 9.38 & $250-700$ \\
\hline
\end{tabular}

For this range of parameters a certain range of ultimate moment of resistance of a beam is calculated. This can be checked with external moment on the beam due to load (self - weight) acting on the beam and the possible number of failure cases can be verified. Thus reliability, which is nothing but the complement of probability of failure, is obtained.

In the present research work, we have assumed a set of inputs such as $\mathbf{b}=\mathbf{2 7 5} \mathrm{mm}, \mathbf{d}=\mathbf{3 2 0} \mathrm{mm}, \mathbf{f}_{\mathbf{c k}}=\mathbf{2 0} \mathrm{MPa}$, $\mathbf{f}_{\mathbf{y}}=\mathbf{4 1 5} \mathrm{MPa}$ for which ten thousand random variables are generated and the corresponding values obtained in Excel files are called in MATLAB code by 'dlmread' command. For any given $\mathbf{P}_{\mathbf{c}}, \mathbf{P}_{\mathbf{t}}$ and span of the beam the reliability analysis of beam is calculated. If $\boldsymbol{M}_{\boldsymbol{u r} \boldsymbol{r}^{-}}<\boldsymbol{M}_{\boldsymbol{e}}$ the beam is expected to fail. Thus counting the probable cases of failure we can evaluate the reliability of the reinforced beam.

\section{RESULTS}

Using the MATLAB generated code, the ultimate moment of resistance of any doubly reinforced beam can be calculated for the given percentage of compression and tension steel and span of the beam. The code written is flexible for any given reinforced beam, the 'dlmread' command takes the set of random variables generated by various mathematical simulations for the given 
corresponding input data. The quantification of number of cases of probabilistic failure and the complementary reliability analysis is done. This verifies the reliability of the beam.

As mentioned earlier, we have assumed a beam of width $b=275 \mathrm{~mm}$, effective depth $d=320$, grade of concrete fck $=20 \mathrm{MPa}$ and grade of steel fy $=415$ and generated a set of 10,000 random variables by using MATLAB inbuilt command and considering the distribution and mean and co-efficient of variations as mentioned above in the Tables $4 \& 5$ and tested the code for various cases of $\mathrm{Pc}$ and $\mathrm{Pt}$ and performed the reliability analysis of the beam with the given input data and, we have mentioned two such results. Likewise the probabilistic study can be carried for various other combinations of input data and reliability of the beam can be verified. Two examples have been cited for each of the cases, when the beam is singly reinforced and doubly reinforced.

Test result 1:

Input data: $\mathrm{Pc}=0.5, \mathrm{Pt}=1.0$, span of beam $=6000 \mathrm{~mm}$; $\mathrm{d}^{\prime}=40 \mathrm{~mm}$;

Probability of failure $(\mathrm{Pf})=0$; Reliability $=1$

Hence for this combination of given input the beam is very reliable.

Test result 2:

Input data: $\mathrm{Pc}=0.0, \mathrm{Pt}=0.9$, span of beam $=6000 \mathrm{~mm}$; $\mathrm{d}^{\prime}=50 \mathrm{~mm}$;

Probability of failure $(\mathrm{Pf})=0.0263$; Reliability $=0.9737$

For the given input data the beam is reliable for 97 beams out of 100 , hence this combination can be discarded.

\section{Conclusions}

According to the study, the probability of failure is computed for the various possible cases of input, where in 10,000 possible values for each of the random variables are considered including uncertainties and neglecting partial safety factors for the materials. The computation of the Ultimate Moment resistant capacity of the beams is in order to obtain the true strength and failure possibility of a beam. The results can be concluded as:

1) For any given doubly reinforced beam the probability of failure has been obtained as zero.

2) Whereas for a singly reinforced beam the probability of failure depends upon the percentage of steel.

\section{REFERENCES}

[1]. Structural Reliability Methods by O. Ditlevsen and H.O. Madsen

[2]. Reinforced concrete design by S. UnniKrishna Pillai \& Devdas Menon, Tata McGraw Hill Education Private Limited.

[3]. Limit State Design of Reinforced Concrete by P.C. Varghese,second Edition, Eastern Economy Edition.

[4]. Ravi Chugh and Devdas Menon, "Design aids for estimation of shear in seismic design of RC beams", Indian Concrete Journal, Vol. 79, No. 3, pp 22-28, March 2005.

[5]. Reliability of structures by Andrej S. Nowak \& Kevin R. Collins, Tata McGraw Hill Education Private Limited.

[6]. Reliability engineering and risk analysis, A Pratical Guide by Mohammad Modrres, Mark Kaminskly, Vasiliy Krivtsov Marcel Dekker Inc.

[7]. Structural Analysis, An unifiedclassical and matrix approach by A. Ghali, A.M. Neville, T. G. Brown,6th Edition, Spon Press.

[8]. Structural reliability analysis and prediction by Robert Melchers, Second Edition (John Wiley \& Sons, ISBN 0471-98771-9).

[9]. Reliability Analysis and design of structures by R. Ranganathan.

[10]. Getting started with MATLAB by Rudra Pratap, Oxford University Press.

[11]. Probability, Reliability and statistical methods in engineering design by Achinthya Haldar \&Sankaran Mahadevan,John Wiley 2000

[12]. Applications to reliability analysis by Enrique Castilloa, Alfonso Fernández-Cantelib, Roberto Mínguezc.

[13]. Teaching Structural Reliability using the Internet and LabVIEW by Paiboon Lertwongkornkit.

[14]. www.mathworks.com 